\title{
Relationship of Trauma From Occlusion and Severity of Periodontitis on Patients in Periodontal Clinic RSGMP FKG USU
}

\author{
Immanuel Budi Hutabarat \\ Undergraduate Student \\ Faculty of Dentistry, Universitas Sumatera Utara \\ Medan, Indonesia
}

\begin{abstract}
Trauma from occlusion and periodontitis are two factors that result in periodontal destruction. Many researches about the relationship between trauma from occlusion and periodontitis have been discussed controversially since the 20th century. The aim of this study is to determine the relationship of trauma from occlusion and severity of periodontitis based on the quality and to describe how the periodontal destruction based on the quantity on trauma from occlusion in periodontitis teeth. This study is a descriptive analytics study with cross sectional design. This study conducted in Periodontal Clinic RSGMP FKG USU on June-July 2017. The subject was taken with accidental sampling method with total 8 patients $(52$ teeth periodontitis with trauma from occlusion and 53 periodontitis teeth with balanced contact occlusion) that meet the inclusion criteria, taken by accidental sampling method. To determine periodontitis teeth with trauma from occlusion and periodontitis with balance contact were done using articulating paper. Measurement of pocket depth and clinical attachment loss were performed in both groups to determine the periodontal destruction based on quantity. Teeth in both groups were then categorized according to the severity of periodontitis (mild, moderate and severe) with loss of clinical attachment. Then the data were compared and analyzed to know the relationship of trauma from occlusion and severity of periodontitis that based on clinical attachment loss. The results of this study showed a higher mean difference in periodontitis teeth with trauma from occlusion than periodontitis teeth with balanced contact with differences in pocket depth and clinical attachment loss. Results showed that there was a significant relationship was found between traumas from occlusion severity of periodontitis.
\end{abstract}

Keywords-trauma from occlusion, periodontitis, pocket depth, clinical attachment loss, severity of periodontitis

\section{INTRODUCTION}

Trauma from occlusion is defined as an injury that occurs in the periodontium as the accepted occlusal pressure has exceeded the capacity of its adaptive capacity [1-3]. Trauma from occlusion is classified as primary and secondary, where primary trauma from occlusion results from abnormal occlusal forces on the relatively sound periodontal structure, whereas secondary trauma from occlusion results from physiologic or abnormal occlusal forces that act on a

\author{
Rini Octavia Nasution \\ Department of Periodontology \\ Faculty of Dentistry, Universitas Sumatera Utara \\ Medan, Indonesia
}

dentition that is seriously weakened by the loss of supporting alveolar bone. These forces when within the normal range can be well adapted by the tooth supporting soft tissues, whereas excessive occlusal forces can lead to pathological changes in the soft tissues. These forces are normally described in terms of magnitude, direction, duration, and frequency.

Periodontitis is defined as an inflammatory disease of the supporting tissue of the teeth caused by specific microorganism or groups of a specific microorganism, resulting in progressive destruction of the periodontal ligament and alveolar bone with increased probing depth formation, recession, or both [4]. Chronic periodontitis is the most common form of periodontitis. Chronic periodontitis is associated with the accumulation of plaque and calculus and generally has a slow-tomoderate rate of disease progression, but periods of more rapid destruction may be caused by the impact of local, systemic, or environmental factors that may influence the normal host-bacteria interaction [4].

Dysregulated inflammatory responses and intraoral colonization with specific pathogens have been widely accepted as the main causative agents of periodontal disease. However, this does not mean that role of occlusal forces as risk factor for the progression of periodontal disease is fully understood [5]. Trauma from occlusion and periodontitis, both process results in injury to the attachment apparatus because the periodontium is unable to cope with the pathological insult which it experiences [6]. When inflammation extends from the gingival into the supporting periodontal structure, (when gingivitis become periodontitis), plaque-induced inflammation enters the zone influenced by occlusion, which Glickman has called the zone of co-destruction [4].

The influence of occlusal force on periodontitis has been discussed controversially since the 20th century [7]. Many animal experiments and clinical studies have investigated the role of occlusion in the pathogenesis of periodontitis. The results suggest that premature contact or excessive occlusal force could be an etiologic factor in the progression of periodontitis through inflammation that spreads into the deep portion of the periodontium. Based on these findings, vertical alveolar bone resorption and infrabony defects should be considered a result of occlusal trauma [8]. 
Nunn and Harell reported the retrospective findings of a group of patients with periodontitis in which the analysis was based on the measurement of the loss of attachment of each individual tooth and the presence or absence of occlusal interferences [9]. Branschofsky et al conducted a study to determine the relationship between secondary trauma from occlusion and severity of periodontitis. The results of this study indicate that secondary trauma from occlusion is found in patients with periodontitis and there is a significant relationship between the numbers of trauma from occlusion teeth with periodontitis severity. The prevalence of trauma from occlusion also positively correlates with loss of attachment [5]. This study is in accordance with the study of Nakatsu et al on the role of trauma from occlusion in accelerating loss of attachment through experimental studies of artificial periodontitis in rats. The results showed that there was a significant increase in attachment loss and osteoclast counts in the trauma from occlusion group of rats and inflammation in the periodontal tissues compared to rats who suffered only trauma from occlusion or periodontal inflammation alone [10].

Different results were obtained in a study conducted by Jin and Cao on the clinical diagnosis of trauma from occlusion and its relation to the severity of periodontitis. This study aims to determine the reliability of some signs of trauma from occlusion and its relation to the severity of periodontitis. The results of this study indicate that there is no significant relationship between traumas from occlusion with increased periodontal attachment loss. Pihlstrom et al reported similar results and concluded that there was no correlation between occlusal contacts in centric relation; working, nonworking, or protrusive positions; and the severity of periodontitis. However, although Jin and $\mathrm{Cao}$ and Pihlstrom reported that teeth showing fremitus had deeper PPD, more attachment loss, and lower radiographic bone height than teeth without fremitus, they did not conclude that there is a relationship between trauma from occlusion and periodontitis [5].

From several studies, there are different opinion between the condition and clinical signs of trauma from occlusion and its relation to the severity of periodontitis. Therefore, the authors feel the need to conduct research on the relationship of trauma from occlusion with the severity of periodontitis in the Periodontal Clinic RSGMP FKG USU.

\section{MATERIALS AND METHODS}

This research is a descriptive analytic research with cross-sectional design done in Periodontal Clinic RSGMP FKG USU in June-July 2017. The subject was taken with accidental sampling method with total 8 patients (52 teeth periodontitis with trauma from occlusion and 53 periodontitis teeth with balanced contact occlusion).

The inclusion criteria of this study were generalized chronic periodontitis patients with secondary trauma from occlusion and had not received periodontal treatment during the last 6 months. Exclusion criteria from this study were aggressive periodontitis, patients had fewer than 20 teeth, had systemic disease, ever receive temporomandibular joint treatment, have craniomandibular dysfunction, using denture, and have received orthodontic treatment.

Clinical examination was conducted in the oral cavity in periodontitis patients, then the number of teeth and tooth loss of each patient was recorded, noting the number of teeth that had mobility and the number of teeth that had furcation involvement in each patient.

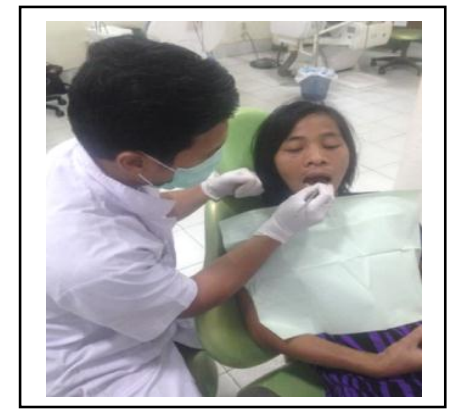

Figure 1. Clinical examination of the oral cavity of the study subjects.

Determination of teeth with trauma from occlusion was done using articulating paper, and to measure the pocket depth and clinical attachment loss was done using UNC-15 periodontal prob.

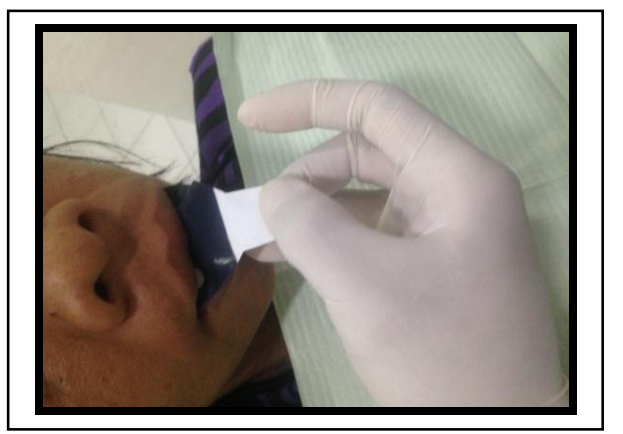

Figure 2. Occlusion contact examination using articulating paper.

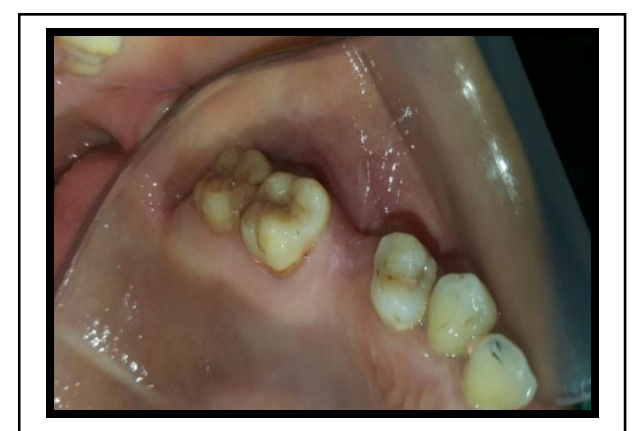

Figure 3. Tooth after examination with articulating paper.

Determination of the quality of trauma from occlusion is done by connecting the number of teeth with trauma from occlusion with the severity of periodontitis. The severity of periodontitis is categorized by the loss of clinical attachment, where mild periodontitis $1-2 \mathrm{~mm}$, moderate periodontitis $2-4 \mathrm{~mm}$, 
and severe periodontitis $\geq 5 \mathrm{~mm}$. Determination of periodontal tissue destruction was done by comparing the mean of pocket depth and loss of clinical attachment of dental periodontitis with trauma from occlusion and dental periodontitis with balanced contact.

The average comparison of periodontitis teeth with trauma from occlusion and balanced contact was done by a statistical test. After that, periodontitis teeth were categorized based on the severity of periodontitis for of each tooth, Chi-Square test was performed to determine the relationship between trauma from the occlusion and severity of periodontitis.

\section{RESULTS}

This study was conducted at the Periodontal Clinic RSGMP FKG USU with total 8 subjects with 52 teeth periodontitis with trauma from occlusion and 53 tooth periodontitis with a balanced contact in June to July 2017. Data distribution of study subjects is shown in Table I.

TABLE I. DISTRIBUTION OF FREQUENCY OF RESEARCH SUBJECTS

\begin{tabular}{|l|c|c|}
\hline & $\mathbf{n}$ & $\mathbf{\%}$ \\
\hline Trauma from occlusion & 52 & 49.5 \\
\hline Balanced contact & 53 & 50.5 \\
\hline
\end{tabular}

Table II showed the pocket depth of periodontitis teeth with trauma from occlusion and balanced contact. The average ratio of pocket depth to trauma from occlusion appears to be greater than that of the teeth with balanced contact. $(4.30 \pm 2.18$ and $3.70 \pm 1.98)$.

TABLE II. DESCRIPTIVE DATA OF RESEARCH SUBJECTS BASED ON POCKET DEPTH

\begin{tabular}{|l|c|c|c|}
\hline & $\begin{array}{c}\text { Minimum } \\
(\mathbf{m m})\end{array}$ & $\begin{array}{c}\text { Maximum } \\
(\mathbf{m m})\end{array}$ & $\begin{array}{c}\text { Mean } \pm \\
\text { SD }\end{array}$ \\
\hline Trauma from occlusion & 1.17 & 11.67 & $4.30 \pm 2.18$ \\
\hline Balanced contact & 1.67 & 9 & $3.70 \pm 1.98$ \\
\hline
\end{tabular}

Table III showed the clinical attachment loss of trauma from occlusion and balanced contact. There was a greater difference of average score between the trauma from occlusion teeth than balanced contact. $(7.33 \pm 2.75$ and $5.55 \pm 2.44)$.

TABLE III. DESCRIPTIVE DATA OF RESEARCH SUBJECTS BASED ON CLINICAL ATTACHMENT LOSS

\begin{tabular}{|l|c|c|c|}
\hline & $\begin{array}{c}\text { Minimum } \\
(\mathbf{m m})\end{array}$ & $\begin{array}{c}\text { Maximum } \\
(\mathbf{m m})\end{array}$ & Mean \pm SD \\
\hline Trauma from occlusion & 3.0 & 14.17 & $7.33 \pm 2.75$ \\
\hline Balanced contact & 1.67 & 11 & $5.55 \pm 2.44$ \\
\hline
\end{tabular}

Table IV showed the severity of periodontitis based on the clinical attachment loss between trauma from occlusion and balanced contact. There was more periodontitis with more severe levels of teeth with trauma from occlusion than teeth with balanced contact. The results of statistical tests showed that based on the distribution of the number of trauma from occlusion and balanced contact teeth associated with the severity of periodontitis, there was a significant relationship between trauma from occlusion and severity of periodontitis $(\mathrm{p}=0.001)$.

TABLE IV. DESCRIPTIVE DATA AND ANALYSIS OF THE RELATIONSHIP BETWEEN TRAUMA FROM OCCLUSION AND SEVERITY OF PERIDONTITIS BASED ON CLINICAL ATTACHMENT LOSS

\begin{tabular}{|c|c|c|c|c|c|}
\hline Severity & $\begin{array}{l}\text { Trauma from } \\
\text { occlusion (n) }\end{array}$ & $\%$ & $\begin{array}{c}\text { Balanced } \\
\text { contact (n) }\end{array}$ & $\%$ & $\mathbf{p}$ \\
\hline Mild & 0 & 0 & 7 & 13.2 & \multirow{3}{*}{$0.001^{\mathrm{a}}$} \\
\hline Moderate & 10 & 19.2 & 18 & 34 & \\
\hline Severe & 42 & 80.8 & 28 & 52.8 & \\
\hline
\end{tabular}

\section{DISCUSSION}

Trauma from occlusion is a condition of injury to the periodontium tissue as the accepted occlusal pressure has exceeded its adaptive capacity and periodontitis is an inflammatory condition of the periodontium tissue due to bacterial plaque causing periodontal ligament damage, alveolar bone destruction, and causes increased pocket depth, recession, and attachment loss [4].

Periodontal disease is a multifactorial and etiological disease. The cause of periodontitis is bacterial plaque. Excessive occlusal pressure can affect the periodontitis state according to the Glickman theory which stated that the spread of inflammatory lesions by bacterial plaque and occlusal pressure can affect each other through the zone irritation and zone of co-destruction [11-13].

The aim of this study was to determine the correlation of quality of trauma from occlusion and the severity of periodontitis and to know the description of the quantity of periodontal destruction of teeth with trauma from occlusion. Subjects in the study were teeth of chronic periodontitis patients who were divided into two groups, periodontitis teeth with trauma from occlusion and periodontitis teeth with balanced contact. The researcher took the patient's dental samples to be subjected to research based on the dental occlusion contacts. To determine the quantity of trauma from occlusion, the comparison between the pocket depth and the loss of attachment between the two groups and to determine the quality of the trauma from occlusion was done by comparison of two groups based on the severity of periodontitis of each tooth.

The results of this study showed an average difference in pocket depth between teeth with trauma from occlusion than balanced contact groups. This is consistent with the results of research by Jin and Cao and Nunn and Harell which suggest there is a higher pocket depth difference in trauma teeth from occlusion than balanced contact [5]. However, the results of research by Jin and Cao stated that there was no significant difference in pocket depth between the teeth of trauma from occlusion and balanced contact [14].

In clinical attachment loss, there was a higher average loss of clinical attachment in the trauma groups than balanced contact groups. The results of this study are supported by research conducted by Nakatsu et al who conducted experimental studies on rats that were divided into three groups, teeth with trauma, teeth with inflammation, and trauma from occlusion teeth with 
inflammation. The results showed that there was a significant increase in the value of clinical attachment loss between the trauma teeth and inflammation compared to the other group [10]. However, the results of this study do not match the results of a study conducted by Jin and Cao which stated that there wasn't any difference between clinical attachment loss of trauma from occlusion and balanced contact. The difference in the results of this study is due to the research of Jin and Cao only studied subjects with moderate and severe periodontitis category alone, and they did not involve patients with mild periodontitis [7].

The results of this research on the relationship between trauma from occlusion and severity of periodontitis were done by grouping each of the teeth in both groups with the severity of periodontitis. The statistical test results indicated that there was a significant relationship between trauma from occlusion compared to teeth with balanced contact. The results of this study in accordance with research conducted by Branchofsky et al which also stated there was a relationship between the severity of periodontitis and trauma from occlusion [5].

Glickman's theory states that the role of bacteria occurs only in the irritation zone (gingival margin) and the combination of bacterial role and occlusal pressure occurring in the co-destructive zone. The pocket depth is measured from the gingival margin to the pocket base where changes in pocket depth are only affected by the irritation zone. In teeth with trauma from occlusion, large gingival recessions are found so that occlusal forces do not affect the depth of the pockets formed. In clinical attachment loss measured from the cementenamel junction pocket and the severity of periodontitis is affected by the co-destructive zone where there is a combination of the role of bacterial plaque and occlusal forces that leads to gingival recession and greater clinical attachment loss.

Although trauma from occlusion has a role in causing the severity of periodontal diseases, bacterial plaque is the most important factor in influencing the severity of periodontal disease. This is consistent with the Consensus Report on Periodontal Disease in 1999 that alleged occlusal trauma may cause injury to the periodontal tissue resulting from excessive occlusal forces but occlusal forces alone cannot cause gingival diseases associated with bacterial plaque and also attachment loss in periodontitis [15].

Burgett et al conducted a controlled test study to evaluate the effects of occlusal adjustment after periodontal treatment. Subjects in this study were divided into patients with occlusal adjustment and patients without occlusal adjustment. The results of this study showed that patients with occlusal adjustment significantly had a good healing and improved of attachment level compared to subjects without occlusal adjustment [16].

Therefore, it is necessary to increase the awareness in maintaining oral health so that people can avoid periodontal disease and trauma from occlusion as a factor that can aggravate the periodontal disease. Appropriate treatment procedures also need to be considered by the dentist in treating patients with periodontitis exacerbated by trauma from occlusion.

Based on the results it is conclude that there is a relationship between trauma from occlusion with the severity of periodontitis. Based on the description of quantity in periodontal destruction, there is a difference in mean of pocket depth and higher loss of clinical attachment in periodontitis teeth with trauma from occlusion compared with balanced contact teeth.

\section{REFERENCES}

[1] T. Ashraf, S.M. Jan, R. Behal, R. Khairat, "Role of occlusion in the etiopathogenesis of periodontal diseases-A review," IJCPHR., vol. 1(1), pp. 35-37, 2016.

[2] F.A. Carranza, Periodontal respons to external forces. In: M.G Newman, H.H. Takei, P.R. Klokkevold, F.A. Carranza, Clinical periodontology, $11^{\text {th }}$ ed., Philadelphia: W.B Saunders Co., 2012, pp. 151-156.

[3] M.R. Sanadi, L.R. Chelani, S.R. Bhakkand, J.K. Sheth, "Role of trauma from occlusion in periodontal disease-A controversy," IOSR-JDMS., vol. 15(9), pp. 118-122, 2016.

[4] J.E. Hinrichs, J.M. Novak, Classfication of diseases and conditions affecting the periodontium.In: M.G. Newman, H.H. Takei, P.R. Klokkevold, F.A. Carranza, Clinical periodontology, $11^{\text {th }}$ ed., Philadelphia: W.B Saunders Co., 2012, pp. 41-44.

[5] M. Branschofsky, T. Beikler, R. Schafer, F. Thomas, H. Lang, "Secondary trauma from occlusion and periodontitis," Quintessence International, vo. 42(6), pp. 515-522, 2011.

[6] S.J. Davies, R.J. Gray, G.J. Linden, J. James, "Occlusal considerations in peridontics," Br. Dent. J., vol. 191(11), pp. 597-604, 2001

[7] L. Jin, C. Cao, "Clinical diagnosis of trauma from occlusion and its relation with severity of periodontitis," J. Clin. Periodontol., vol. 19(2), pp. 92-97, 1992.

[8] Y. Cho, et al., "Rescue of a periodontally compromised tooth by non-surgical treatment: a case report," J. Periodontal Implant Sci., vol. 46(2), pp. 129-134, 2016.

[9] M.J. McDevitt, Occlusal evaluation and therapy. In: M.G Newman, H.H. Takei, F.A. Carranza. Clinical periodontology, $12^{\text {th }}$ ed., Philadelphia: W.B Saunders Co., 2015, pp. 535.

[10] S. Nakatsu, et al., "Occlusal trauma accelerates attachment loss at the onset of experimental periodontitis in rats," J. Periodont. Res., vol. 49, pp. 314-322, 2014.

[11] J. Lindhe, S. Neyman, E. Ingvar, Trauma from Occlusion Periodontal tissues. In: J. Lindhe, N.P. Lang, T. Karring, Clinical periodontology and implant dentistry, $5^{\text {th }}$ ed., Oxford: Blackwell, 2008, pp. 350-351.

[12] S. Reddy. Trauma from occlusion. In: Essentials of clinical periodontology and periodontics, $3^{\text {rd }}$ ed., India: Jaypee Brothers Medical Publisher (P) Ltd., 2011, pp. 94-99.

[13] S. Bathla. Trauma from occlusion and pathologic tooth migration. In: S. Bathla, M. Bathla, Periodontics revisited, $1^{\text {st }}$ ed., India: Jaypee Brothers Medical Publisher (P) Ltd., 2011, pp. 200-202.

[14] S.K. Harrel, M.E. Nunn, "The association of occlusal contacts with the presence of increased periodontal probing depth," J. Clin. Periodontol., vol. 36, pp. 1035-1042, 2009.

[15] K. Meredyk, J. Kostrzewa-Janicka, M. Nedzi-Gora, "The effect of occlusal loading on the periodontal tissues. A literature review. Part I - Occlusion and periodontitis," Dent. Med. Probl., vol. 52, pp. 215-221, 2015

[16] S.K. Harrel, M.E. Nunn, W.W. Hallmon, "Is there an association between occlusion and periodontal destruction?: Yes-occlusal forces can contribute to periodontal destruction," J. Am. Dent. Assoc., vol. 137, pp. 1380-1392, 2006. 